\title{
A psicopatologia para além da dicotomia fato/valor*1
}

\section{Psychopathology beyond the fact/value dichotomy}

Camilo Barbosa Venturi*2

O estatuto ontológico dos transtornos mentais suscita um debate clássico entre perspectivas naturalistas e construcionistas sociais. Com instrumentais conceituais da filosofia da psiquiatria, argumenta-se que, apesar de aparentemente contrárias, posições naturalistas e construcionistas sociais recaem em uma dicotomia fato/valor. Como alternativa a essa polarização clássica, sugere-se uma posição normativista deflacionada, capaz de integrar descrições factuais e valores à psicopatologia.

Palavras-chave: Filosofia da psiquiatria, normativismo, naturalismo, construcionismo social

*1 Trabalho realizado no Instituto de Psicologia da Universidade Federal do Rio de Janeiro, RJ, Br.

*2 Universidade Federal do Rio de Janeiro - UFRJ (Rio de Janeiro, RJ, Brasil). 
Dentre os debates epistemológicos mais conhecidos do campo psicopatológico está o que opõe posições naturalistas a posições construcionistas sociais, no que concerne ao estatuto ontológico dos transtornos mentais. No polo naturalista, os transtornos mentais são concebidos como tipos naturais, dotados de propriedades intrínsecas que independem do modo como nós os descrevemos ou conhecemos. Dentro desta perspectiva, a tarefa de uma ciência psicopatológica seria conhecer essas propriedades essenciais e descrevê-las o mais finamente possível para permitir intervenções clínicas cada vez mais eficazes. Posições naturalistas tendem a ser agrupadas em torno do chamado modelo médico das patologias mentais. Já no outro polo, as categorias psicopatológicas são vistas como construções sociais, isto é, como subprodutos das projeções dos nossos valores, ideais, normas e costumes particulares, sem qualquer propriedade intrínseca independente e, por isso mesmo, sem validade. Argumentos construcionistas sociais são frequentemente associados a posições inspiradas pela antipsiquiatria, para quem as categorias diagnósticas da psicopatologia não pertencem à esfera da ciência, mas da moral.

Este debate clássico ganhou um novo fôlego nas últimas décadas, com a renovação de análises filosóficas dedicadas à psicopatologia, consolidando a filosofia da psiquiatria como um campo disciplinar autônomo e pujante. ${ }^{1} \mathrm{O}$ objetivo deste artigo é retomar esse debate clássico e recolocá-lo a partir de

${ }^{1}$ Para um panorama não exaustivo deste campo na atualidade, cito apenas o periódico Philosophy, Psychiatry, Psychology (https://muse.jhu.edu/journal/164) e a coleção International Perspectives on Philosophy and Psychiatry, publicada pela Oxford University Press. 


\section{ARTIGOS}

novas bases, utilizando para isso instrumentais conceituais da filosofia da psiquiatria. A hipótese sustentada é que, apesar de aparentemente contrárias, tanto posições naturalistas quanto posições construcionistas adotam pressupostos epistemológicos comuns, incorrendo naquilo que Hilary Putnam (2002) denominou "dicotomia fato/valor". De um lado, aposta-se na fundação de uma ciência psicopatológica livre de julgamentos valorativos, como pretende a vertente forte do modelo médico. De outro, intenciona-se "desmascarar" a validade diagnóstica de determinadas categorias psicopatológicas com o argumento de que estas se fundariam em julgamentos de valor contingentes, como sustentam com frequência posições construcionistas sociais. Duas faces da mesma moeda!

Como alternativa a essas duas posições, se fará uso dos argumentos normativistas deflacionados de K. W. M. Fulford (1989, 2001, 2004), para quem todo fenômeno patológico envolve necessariamente descrições factuais emaranhadas com valores. É certo que o campo psicopatológico suscita mais controvérsias acerca da validade diagnóstica de suas categorias do que a medicina dita somática, e que uma linha de corte entre normalidade e patologia se revela pouco nítida ali. Entretanto, isso não se deve à existência de um fosso ontológico entre patologias físicas e mentais, nem significa que os sistemas nosográficos que tratam das primeiras sejam baseados em julgamentos factuais (observação de disfunções orgânicas, por exemplo) ao passo que os das últimas repousem em julgamentos de valor contingentes. Em ambos os campos se lida com fatos associados a valores. O que varia, como se pretende demonstrar, é o grau de compartilhamento coletivo dos critérios descritivos para se estabelecer o valor patológico de um determinado fenômeno. Essa posição não dicotômica lança nova luz sobre o problema, além de nos afastar de querelas inférteis. Conclui-se que toda discussão sobre validade diagnóstica ou sobre a ontologia dos transtornos mentais deveria priorizar um debate amplo sobre o papel desempenhado pelos valores no campo psicopatológico. Essa tomada de posição poderia ser aproximada de um normativismo deflacionado.

Naturalismo e psicopatologia: fatos livres de valor

O debate entre posições naturalistas e normativistas na consideração dos conceitos de doença, normalidade, patologia, saúde etc. ultrapassa em muito o campo da psicopatologia e pode ser observado ao longo da história 
das ideias em diversas tradições. Ainda nos anos 1940, Georges Canguilhem (1995) coloca esse problema no centro da agenda filosófica francesa, com o clássico $O$ normal e o patológico. Na tradição analítica anglo-saxã, essa questão só passou a ocupar um lugar de destaque algumas décadas mais tarde, nos anos 1970 (Giroux, 2010). Um dos responsáveis por isso, além de grande defensor de uma posição naturalista descritivista, foi o filósofo Christopher Boorse, cujos argumentos principais serão resumidos nesta parte. Em seguida, será apresentado como o naturalismo descrito por Boorse reverbera no campo psicopatológico, sobretudo na versão forte do modelo médico.

No cerne da posição de Boorse $(1975,1977,2002)$ está o argumento geral de que o conceito de doença se refere a fenômenos cujas propriedades independem dos valores que nós, seres humanos, lhes atribuímos. Em suma, não seria necessário que alguém imputasse um valor negativo a um determinado conjunto de fenômenos para que um estado patológico fosse determinado. Em uma terminologia filosófica, patologias seriam tipos naturais. Poderíamos traçar um paralelo com os elementos químicos, como o ouro (Zachar, 2000). Como saber se tal elemento diante de nós é ou não ouro? Ora, basta que sejamos capazes de atestar que o seu número atômico é 79 . Afinal de contas, possuir 79 prótons em seu núcleo atômico é uma propriedade essencial do ouro (e apenas dele), independentemente das nossas preferências, juízos, percepções e valores. Tal fato se imporia a nós pela estrutura mesma do mundo, que separa o tipo natural ouro de outros elementos, como o chumbo, de número atômico 82 . O fato de o ouro ser mais apreciado do que o chumbo do ponto de vista social (por sua beleza, raridade, valor econômico etc.) seria secundário à sua propriedade essencial de possuir o número atômico 79. Em Boorse, esse mesmo princípio poderia ser aplicado às doenças: entidades nosológicas, se corretamente descritas em suas propriedades, formariam tipos naturais, separados uns dos outros de modo factual, objetivo, isento de valores, e não de modo contingente e prático, em função de nossos interesses e julgamentos idiossincráticos (Boorse, 1975; 1977).

Apesar de Boorse defender uma concepção teórica de doença inteiramente factual, ele não nega que fenômenos patológicos sejam frequentemente associados a valores negativos, como limitações da capacidade de agir e/ou "sensações de vida contrariada", como dizia Canguilhem (1995). Entretanto, para Boorse, essa fenomenologia do adoecimento não recobre inteiramente o conceito de doença, muito menos deve ser vista como o nível mais fundamental para se defini-lo. Diante disto, ele propõe uma distinção entre os 


\section{ARTIGOS}

significados de "enfermidade" [illness] e "doença" [disease]. ${ }^{2}$ Falamos de enfermidades toda vez que aludimos a uma subclasse das doenças: aquelas "que têm determinadas características normativas refletidas nas instituições da prática médica" (Boorse, 1975, p. 56), ou seja, as que se nos apresentam como suficientemente incapacitantes, graves, indesejáveis, demandando um tratamento especial. Estamos imersos no conceito de enfermidade quando diante de patologias que geram incapacidade para a ação ordinária ou uma série de estados desagradáveis dos quais preferimos nos ver livres. Isso faz da enfermidade um conceito eminentemente prático, aplicado em função de valores, aspirações e do desejo de intervir sobre o que consideramos nocivo e prejudicial.

O significado de enfermidade não recobriria, contudo, todo o campo do patológico. As enfermidades [illnesses] acompanhariam tão somente uma parcela, ou subclasse, das doenças [diseases]. Toda enfermidade é derivada de uma doença, mas nem toda doença é acompanhada de uma enfermidade. Não há uma dependência lógica de mão dupla entre essas duas dimensões. Caso contrário, não seria possível postular que organismos vivos não sencientes (e, portanto, incapazes de experimentar sensações de vida contrariada) possam ficar doentes; ou então que condições fisiológicas nocivas latentes, assintomáticas, constituam estados patológicos. Logo, a definição de um conceito adequado de doença não deveria repousar sobre um significado prático (como o de enfermidade), mas sobre um significado estritamente teórico, a ser analisado pelos instrumentais da biologia, e não da axiologia ou da ética. $\mathrm{O}$ mesmo princípio poderia ser aplicado inversamente à noção de "saúde" que, em um sentido prático, remeteria tão somente à "ausência de enfermidade tratável", mas cujo sentido teórico deveria ser buscado em uma teoria fisiológica dos organismos (Boorse, 1977).

O próximo passo da sua argumentação é apresentar os critérios para se determinar saúde e doença de um ponto de vista estritamente teórico. Tais critérios repousam sobre uma posição funcionalista baseada em noções como desenho natural da espécie, função e classe de referência. Em linhas gerais, Boorse compartilha o postulado evolucionista de que cada espécie

${ }^{2}$ A língua inglesa possui vários vocábulos que em português poderiam ser corretamente traduzidos por "doença", como "disease", "illness", "sickness", "malady", "infirmity"... Na ausência de uma tradução canônica, optamos por traduzir "disease" por "doença" e "illness" por "enfermidade", cientes de que essa opção revela algum grau de arbitrariedade. 
possui um desenho natural que torna a sua vida apta e adaptada ao próprio ambiente. Cada desenho natural seria análogo a um sistema, composto por uma multiplicidade de subsistemas hierarquizados em diversos níveis de complexidade, desde o nível celular, passando pelos órgãos, até o organismo como um todo. Cada um desses sistemas e subsistemas seria responsável por desempenhar determinadas funções naturais, de modo que "o elemento crucial na ideia de desenho biológico é a noção de função natural" (Boorse, 1975, p. 57). Por fim, ele introduz a noção de classe de referência: para se avaliar uma função, há que se levar em conta as especificidades de cada espécie e, dentro da espécie, variáveis populacionais específicas, como sexo e faixa etária. Por exemplo, é um equívoco considerar que esteja doente um bebê de seis meses de idade que não ande, visto que não andar é normal para a sua classe de referência (Boorse, 1977).

A partir dos conceitos apresentados acima, Boorse proporá um conceito teórico de doença como disfunção, definida como falha do organismo (ou de partes dele) para executar funções normais, contrariando assim o desenho natural da espécie, levando-se em conta classes de referência apropriadas. Essa definição teórica de doença permite, segundo Boorse, especificar como patologia qualquer tipo de alteração funcional latente ou assintomática. Além disso, ela tem a vantagem de se aplicar também a seres não sencientes, incapazes de experimentar sofrimento, limitações da ação ordinária, entre outras características típicas da fenomenologia do adoecimento. Assim, se a sua definição de enfermidade é prática e restritiva, sua definição de doença é teórica e abrangente, com pretensões a estabelecer descrições factuais isentas de julgamentos de valor. Inversamente, "o estado de um organismo está teoricamente saudável, isto é, livre de doenças, na medida em que seu modo de funcionamento está de acordo com o desenho natural daquele tipo de organismo" (Boorse, 1975, p. 57; grifo nosso).

O tipo de debate suscitado por Boorse encontra ressonâncias no campo psicopatológico, sobretudo em relação ao estatuto ontológico dos transtornos mentais. As entidades nosográficas de que dispomos deveriam ser pensadas como tipos naturais ou como construções humanas? Seria a sua distinção em classes e famílias um resultado do modo como o mundo é estruturado ou da projeção do nosso interesse de intervir sobre as coisas? Os que defendem, de forma implícita ou explícita, que transtornos mentais devam ser pensados como tipos naturais sustentam um modelo médico da psicopatologia.

Como explicita Damazeux (2013), manuais descritivos, como o DSM-III e seus sucessores, foram diretamente influenciados pelas ideias de Carl 


\section{ARTIGOS}

Hempel. Esse filósofo neoposivista defendia a equiparação de classes diagnósticas a conceitos científicos, desde que obedecidas duas etapas: uma primeira fase de observação, descrição e classificação dos objetos ou eventos; uma segunda fase de estabelecimento de leis gerais e teorias integradoras. Neste sentido, ao isolar síndromes, esses manuais ditos a-teóricos cumpririam a primeira dessas etapas, estando a segunda reservada ao futuro da pesquisa empírica, com o estabelecimento da etiopatologia dos transtornos mentais. Como afirma a filósofa da psiquiatria Rachel Cooper (2007):

Pelo menos implicitamente, a APA almeja construir um sistema de classificação muito parecido com o encontrado na biologia ou na química. As diferenças entre tipos de transtorno mental são pensadas como sendo objetivas e teoricamente importantes, do mesmo modo como as diferenças entre elementos químicos ou espécies biológicas. A APA assume que os transtornos mentais sejam tipos naturais. (pp. 46-47)

Mesmo tendo sido elaborado para fazer avançar a descoberta de marcadores biológicos para os transtornos mentais, tais manuais lidam com o nível explicativo que Boorse (1975) chamava de enfermidade [illness]. Portanto, são inundados de julgamentos valorativos os mais diversos. Por isso mesmo, defensores da versão forte do modelo médico passaram a supor que, apesar de confiáveis, esses manuais ainda apresentariam uma incapacidade constitutiva para desenvolver uma taxonomia causal, livre da confusão da linguagem comum e dos julgamentos valorativos. Em outras palavras, suas categorias diagnósticas não se tornariam conceitos científicos, como sugeria Hempel, e continuariam a reproduzir os seus conhecidos problemas de validade diagnóstica. Como alternativa, o National Institute of Mental Health (NIMH) investe atualmente em um novo sistema nosológico, o Research Domaine Criteria (RDoC), que incorpora informações advindas da genética, dos estudos por neuroimagem e das ciências cognitivas. ${ }^{3}$ Assim, se abriria a via para uma taxonomia causal, menos comprometida com a fenomenologia clínica dos sinais e sintomas. Tal ideal diagnóstico acredita poder estabelecer as categorias diagnósticas a partir da busca de suas propriedades essenciais, de modo

${ }^{3} \mathrm{O}$ NIMH é organismo de pesquisa estatal norte-americano dotado de um orçamento anual bilionário, fato que o transforma na maior instituição de pesquisa sobre os transtornos mentais no mundo. Sobre o projeto do RdoC, ver o site $<$ https://www.nimh.nih. gov/research-priorities/rdoc/index.shtml>. (Acessado em 25 jan. 2018). 
a produzir validade em qualquer contexto ou mundo possível. Atingir a maturidade científica, desta perspectiva, é conseguir revelar correlações estritas entre disfunções de partes do organismo e diagnósticos específicos, realizados como tipos naturais. Isso se coaduna com uma definição de patologia mental que se pretende descritiva, factual, isenta da confusão a-científica dos julgamentos valorativos.

\section{Construcionismo social e psicopatologia: valores livres de fatos}

No outro polo do debate, diametralmente oposto ao modelo médico, encontra-se uma série de programas de pesquisa comumente agrupados em torno da noção de construcionismo social. Essa noção é heterogênea e não se restringe a um debate interno ao campo da saúde ou da psicopatologia. Com muita frequência, ela é utilizada para "desmascarar" toda forma de essencialismo, naturalismo ou "inevitabilismo" presentes nos discursos e nas práticas científicas. O filósofo Ian Hacking, em um estudo epistemológico dedicado ao termo construção social, fez um catálogo não exaustivo dos temas aos quais ela vem sendo aplicada nas últimas décadas: emoções, fatos, gênero, autoria, irmandade, criança telespectadora, cultura homossexual, conhecimento, natureza, quarks, realidade, assassinos em série, mulheres refugiadas, surdez, violência contra a criança, dentre muitos outros et ceteras (Hacking, 1999). Nesta parte, visa-se apresentar algumas nuances envolvendo essa vasta noção de construção social e, em seguida, mostrar como uma atitude construcionista social é frequentemente aplicada ao campo psicopatológico.

A ideia de construção social não é unitária, mas atende a uma multiplicidade de propósitos, designações e agendas. Apesar de tamanha heterogeneidade, orientações construcionistas sociais tendem a compartilhar (embora nem sempre) três atitudes principais. A primeira atitude é afirmar que $X$ não precisa ter existido ou não precisa ser como é, ou seja, X (ou X como o é na atualidade) não é determinado pela natureza das coisas, não é inevitável, não possui qualquer propriedade essencial, é contingente. A segunda atitude vai além e afirma que $\mathrm{X}$ é ruim do modo como está. Apesar de não ser fundamental e necessária, essa atitude é bastante frequente nos estudos construcionistas sociais, dando ensejo a posturas reformistas e desmascaradoras. Finalmente, uma terceira atitude intensifica a segunda, ao dizer que estaríamos muito melhores se $\mathrm{X}$ fosse extinto, ou pelo menos radicalmente transformado. Esta última traz um apelo direto à ação e à militância (Hacking, 1999). 


\section{ARTIGOS}

A ideia de que os transtornos mentais são construções sociais tem sido alvo de inumeráveis programas de pesquisa, de várias escolas e filiações teóricas. Uma atitude construcionista social típica sustenta que as descrições para os transtornos mentais são inseparáveis de culturas locais, sistemas de significação e jogos de poder que definem o que é normal e anormal, racional e irracional, apropriado e inapropriado, funcional e disfuncional, e assim por diante. Em suma, o estabelecimento da legitimidade de uma categoria nosográfica não estaria historicamente submetido à descrição correta de suas propriedades essenciais, mas a fatores externos, como sistemas de crença, lobby de grupos específicos, ideologias, jogos de força ligados a circunstâncias sociais, econômicas e históricas. Isso valeria para temas tão variados quanto o transtorno do estresse pós-traumático (Young, 1995), os manuais de psiquiatria (Kirk \& Kutchins, 2008), o TDA/H (Conrad \& Potter, D, 2000), a esquizofrenia (Boyle, 1990; Barrett, 1998), o autismo (Nadesan, 2005) etc. Nesse aspecto, os estudos construcionistas sociais tendem a adotar uma atitude epistemológica externalista em relação ao estabelecimento das categorias psicopatológicas, em contraste com a atitude internalista própria ao modelo médico.

Alguns comentadores elegem As regras do método sociológico, de Émile Durkheim (parcialmente dedicado ao tema do comportamento desviante), como obra seminal desse tipo de perspectiva (Horwitz, 2013; Lovell \& Moutaud, 2017). Na década de 1930, Ruth Benedict publicou o artigo "Anthropology and the abnormal" (1934), que aplicava as ideias da sociologia do desvio à psicopatologia pela primeira vez (Horwitz, 2013). Como descrevia Benedict, fenômenos que no Ocidente são associados a perturbações mentais, como o comportamento paranoico, as convulsões, os transes, os estados dissociativos etc., em outras culturas pertenceriam à esfera da normalidade, podendo até ser valorizados. Assim, para Benedict e seus afiliados teóricos, os transtornos mentais teriam tão somente uma ontologia subjetiva, relativa, visto que sua definição depende de regras e valores humanos em contexto.

Tal postura epistemológica em relação aos transtornos mentais encontrou grande acolhida nas décadas de 1960 e 1970, em obras que se aproximaram mais ou menos do que ficou conhecido como antipsiquiatria. Talvez seja supérfluo falar do impacto cultural que $A$ história da loucura na Idade Clássica, de Michel Foucault, teve em muitos contextos intelectuais desde a publicação da sua primeira edição, em 1961. Independentemente dos complicados meandros argumentativos erigidos por Foucault nessa obra, com 
consequências teóricas várias, temos que o conceito de doença mental é trabalhado ali como algo historicamente situado na modernidade e, portanto, como algo contingente, que só pôde ser construído dentro de uma determinada épistémè (Foucault, 1972). Ao pretender desmascarar a retórica de cientificidade e de progresso da psiquiatria, há um olhar crítico implícito contra a sua existência como disciplina legítima.

Outro grande produto da cultura antipsiquiátrica é a obra de Thomas Scheff. Em um estudo clássico publicado pela primeira vez em 1966, o sociólogo americano afirmava que os sinais e sintomas psicopatológicos não expressariam distúrbios dos indivíduos, mas violações de regras sociais estabelecidas. Segundo a sua "teoria da rotulação", haveria um impulso para tornar condutas desviantes inteligíveis aos nossos olhos, fornecendo-lhes um nome, uma tipologia e uma explicação, de modo a gerar uma "resposta social" adequada. Assim, em uma espécie de nominalismo, Scheff acreditava que as categorias psicopatológicas seriam tão somente rótulos que atribuímos a certos grupos que tendem ao desvio das normas estabelecidas. Logo, esse tipo de desvio ganharia inteligibilidade e uma resposta social adequada. Crítico da psiquiatria, Scheff argumentava que o ato diagnóstico traz efeitos iatrogênicos, produzindo estigma e danos à identidade pessoal dos sujeitos rotulados. Neste processo de rotulação, seria proposto um determinado "papel social" (altamente desvalorizado) para esses sujeitos, isto é, um lugar que se espera que eles ocupem. Pela interação com esses discursos, rótulos, explicações e práticas estabelecidos, o sujeito acabaria assumindo para si tal papel, preenchendo todos os requisitos esperados de um "doente mental" (Scheff, 1984).

Essa forma de construcionismo social expressa pela antipsiquiatria fica ainda mais clara quando analisamos a obra de Thomas Szasz, autor do clássico $O$ mito da doença mental (1961). Mas o que significa dizer que doenças mentais são mitos? $O$ argumento se desenvolve por partes. Em primeiro lugar, ecoando ideias oriundas da sociologia do desvio, Szasz afirma que transtornos mentais são diagnosticados quando determinados sujeitos incorrem em violações de normas éticas, legais e psicossociais sustentadas pelo status quo. Para esse crítico feroz do modelo médico, tal atitude diagnóstica entraria em conflito frontal com o significado de "doença". Toda patologia, para ser diagnosticada, deveria envolver uma ruptura com normas factuais, definidas pela integridade estrutural e funcional dos organismos. No caso das ditas patologias mentais, como seguimos sem o estabelecimento de marcadores biológicos insuspeitos, esse critério de definição do patológico não seria preenchido. Portanto, associar as categorias diagnósticas 


\section{ARTIGOS}

da psiquiatria ao campo das doenças consistiria em erro categorial. Para Szasz, somente se poderia falar em "doença mental" em um sentido metafórico, popular, mas nunca científico, literal. Isso não significa que o conceito de transtorno mental não aluda a dimensões problemáticas da vida. Pelo contrário, tendemos a utilizar esse conceito metaforicamente quando estamos diante de "problemas do viver" [living problems], que envolvem violações de normas éticas, legais e psicossociais. Mas isso não pertenceria ao campo do patológico stricto senso, mas à dimensão moral da vida humana. Logo, não deveria convocar a uma reflexão médico-científica, mas trágico-existencial. Sua conclusão final: a categoria "patologia mental" é da ordem do mito, se tomada em sentido literal (Szasz, 1961).

É interessante notar que a crítica que Szasz endereça às categorias psicopatológicas repousa no fato de elas serem definidas a partir de juízos de valor. A seu ver, é isso que fragiliza a sua legitimidade e faz da psiquiatria uma pseudociência. Por outro lado, o critério utilizado para conferir legitimidade a uma determinada condição patológica é justamente o fato de essa não envolver julgamentos valorativos, mas apenas desvios de normas factuais, definidas pela integridade estrutural e funcional dos organismos. Nossa hipótese é que, apesar de aparentemente adversários, tanto a versão forte do modelo médico quanto o construcionismo social ao estilo de Szasz recaem no problema epistemológico da dicotomia fato/valor (Putnam, 2002). Será proposta uma recolocação da questão, com base na argumentação de K. W. M. Fulford, de modo a oferecer subsídios para uma perspectiva normativista deflacionada que escape deste problema.

\section{A psicopatologia para além da dicotomia fato/valor}

Hilary Putnam (2002) aponta como na história da filosofia moderna houve uma tendência a se estabelecer uma dicotomia entre julgamentos de valor e afirmações factuais. É comum entre nós a ideia de que a ciência pura e verdadeira só lida com fatos, concebidos como descrições verificáveis pela experiência, longe de qualquer contaminação por juízos valorativos. Isso supostamente lhe conferiria objetividade. Os juízos de valor, por sua vez, seriam reduzidos a meras impressões pessoais, inundadas de subjetivismo, não verificáveis pela experiência e, portanto, fora do âmbito da razão científica. Logo, diz essa tradição, para estabelecer enunciados científicos válidos se deve por bem eliminar qualquer referência ao campo dos valores. Putnam 
se insurgirá contra essa posição típica, que ele (junto com outros da linhagem pragmatista) acusa de dualismo. Há um entrelaçamento inelutável entre fatos e valores no campo da linguagem e, por extensão, em qualquer enunciado ou prática científica. Pode-se estabelecer distinções entre fatos e valores, úteis em certos contextos para determinados propósitos, mas isso não implica dicotomia ontológica. ${ }^{4}$ Pensar o contrário é adotar uma postura metafísica. Um dos exemplos a que ele recorre para defender seu ponto de vista envolve a palavra "cruel", que costuma envolver aspectos éticos e normativos. Todavia, um historiador pode muito bem utilizar o termo "cruel" em um sentido francamente descritivo, ao dizer que um determinado monarca foi cruel com seus inimigos. Assim, "“cruel' simplesmente ignora a suposta dicotomia fato/valor e permite de bom grado ser às vezes utilizado para um propósito normativo e às vezes como um termo descritivo" (Putnam, 2002, p. 35).

Essa querela filosófica abstrata tem íntima conexão com o debate proposto neste artigo. Argumentamos que tanto o modelo médico quanto variações do construcionismo social tendem a se comprometer com uma dicotomia fato/valor. Em um polo, sustenta-se que a ciência psiquiátrica, no caminho para a maturidade, deveria conseguir expurgar de si a contaminação por valores, atendo-se tão somente a fatos e descrições. No polo oposto, desqualifica-se qualquer possibilidade de uma ciência psiquiátrica, na medida em que as categorias psicopatológicas seriam construções ontologicamente subjetivas, sem qualquer dimensão descritiva envolvida. Ambos carregando implicitamente pressupostos do dualismo moderno!

Como alternativa a esse tipo de dicotomia, se recolocará o problema da validade diagnóstica na psicopatologia a partir das reflexões de K. W. M. Fulford, para embasarmos a defesa de um normativismo deflacionado. Em várias de suas publicações individuais e coletivas dedicadas a esse problema (Fulford, 1989, 2001, 2004; Fulford, Broome Stanghellini \& Thornton, 2005; Fulford, Thornton \& Graham, 2006), esse psiquiatra e filósofo britânico sugere um diagnóstico analítico interessante: apesar de aparentemente adversários, adotando conclusões radicalmente contrárias, os argumentos das versões fortes do modelo médico e do construcionismo social apresentam semelhanças fundamentais:

${ }^{4}$ Putnam toma emprestado de John Dewey a ideia de que uma dicotomia difere de uma distinção. Se a dicotomia tem que valer para todos os casos, dividindo o mundo ao meio em função de diferenças essenciais, uma distinção é pragmaticamente delineada, útil para certos propósitos. 


\section{ARTIGOS}

1) Ambas as posições adotam a premissa de que a noção de transtorno mental é conceitualmente problemática, obscura, demandando clarificação. No modelo médico, isso se expressa nos embates internos sobre o melhor modo de se estabelecer categorias diagnósticas, de determinar a sua validade e a sua confiabilidade. Na versão construcionista social, a simples disputa em torno da legitimidade das categorias psicopatológicas já indica uma suspeita em torno da transparência e da estabilidade do seu significado.

2) Implicitamente, tanto uma quanto a outra perspectiva admitem que o que torna o conceito de transtorno mental problemático é o fato de este repousar em valores. No modelo médico, isso é explicitado pela tentativa de se construir sistemas nosográficos que dependam o mínimo possível da observação clínica e o máximo possível de signos objetivamente aferíveis (como no projeto RDoC). No construcionismo social, isso é atestado pela atitude de desmascaramento de uma suposta ordem natural, que esconderia sistemas de significação variáveis, valores sociais contingentes ou propósitos políticos não declarados.

3) Por fim, há uma asserção implícita nas duas posições de que as doenças físicas seriam menos problemáticas do ponto de vista conceitual do que os transtornos mentais. No modelo médico, isso é evidente, na medida em que se acredita que a maturidade do campo psicopatológico seria atingida com a transformação de síndromes clínicas em doenças com etiologia e mecanismos de ação definidos, tal como ocorre com mais frequência na dita medicina somática. No modelo construcionista isso se evidencia no instante em que autores como Szasz utilizam certa descrição de doença física para denunciar o quanto as categorias psicopatológicas não se referem a normas factuais, mas a desvios de ordem ética, legal e psicossocial. Em ambos os casos, acredita-se que as doenças físicas sejam menos problemáticas conceitualmente por repousarem sobre descrições isentas de valor, ao estilo do que sugere Christopher Boorse.

Diante desse diagnóstico, Fulford propõe uma estratégia diferente de ataque ao problema. Em vez de analisarmos as conclusões opostas sustentadas por ambas as posições, devemos questionar aquilo que elas têm em comum: a premissa de que as categorias psicopatológicas apresentam fragilidades epistêmicas por dependerem de julgamentos valorativos; e a premissa de que um conceito menos problemático de patologia não repousaria em julgamentos valorativos, mas em normas factuais, puramente descritivas.

Para Fulford et al. (2005), os construcionistas sociais estão corretos ao chamarem a nossa atenção para a inelutável dimensão valorativa, moral ou 
contextual das categorias psicopatológicas. É óbvio que o DSM-5, o CID-10 e seus derivados são catálogos plenos de julgamentos de valor! Não há dúvidas de que diagnósticos como Disforia de Gênero, TDA/H, Transtorno Opositivo-Desafiador, Fobia Social... envolvam em alguma medida dimensões normativas. Mas não é isso (ou, pelo menos, não deveria sê-lo), todavia, que faz com que tais categorias suscitem controvérsias relacionadas à sua validade diagnóstica, como veremos. Os defensores do modelo médico, por sua vez, também têm razão ao insistir na equiparação ontológica entre patologias físicas e mentais, bem como na integração do campo psicopatológico ao restante das disciplinas médicas. Entretanto, o seu equívoco central seria pressupor que o avanço da pesquisa sobre as categorias psicopatológicas deveria acompanhar uma substituição progressiva de julgamentos valorativos por descrições factuais, isentas de valor. Como se os problemas de validade diagnóstica das categorias nosográficas se devessem à intrusão de julgamentos de valor na pesquisa científica!

Discordando parcialmente de ambos os polos do debate, Fulford defenderá o entrelaçamento de fatos e valores no significado das patologias físicas e mentais. Para embasar suas conclusões, apoia-se sobre a filosofia de R. M. Hare a respeito das propriedades lógicas dos termos de valor. Segundo Hare, todo significado de afirmações valorativas contém simultaneamente dois elementos embutidos: um factual e um valorativo. Isso acontece porque os critérios utilizados para atribuir valor a algo seriam sempre critérios descritivos (Fulford, 1989). De modo mais concreto, tomemos como exemplo a seguinte afirmação: "esses morangos estão bons". Naturalmente, trata-se de um julgamento de valor, porque implica uma prescrição ou ação: "bons para comer". Contudo, também há nessa afirmação uma dimensão factual, na medida em que a grande maioria de nós compartilha os mesmos critérios para se descrever um "morango bom": firme, suculento, doce, sem bichos, vermelhinho etc. Como se vê, o predicado valorativo "bom" é inseparável de descrições factuais, que não envolvem diretamente valores. Logo, descrição e prescrição, fato e valor, encontram-se inevitavelmente emaranhados no significado desta afirmação.

Mas o argumento não para aí. No cotidiano, pode acontecer de os elementos factuais assumirem a dianteira do significado de uma afirmação, enquanto às vezes são os elementos valorativos que ocupam o centro da cena. Para Hare, o que determina essa supremacia é o nível de compartilhamento dos critérios utilizados para se descrever o valor de algo. Quanto mais compartilhados forem esses critérios, mais os elementos factuais, 


\section{ARTIGOS}

descritivos, assumem o protagonismo do significado de uma afirmação, e vice-versa (Fulford, 1989). Por exemplo, se a maioria de nós é capaz de descrever o que é um "morango bom" isso significa que compartilhamos de forma ampla os critérios factuais utilizados para executarmos esse tipo de julgamento. Consequentemente, os elementos factuais de "morango bom" ocupam um lugar de destaque em seu significado e ficamos com a impressão de que julgar o que é um "morango bom" não é difícil ou problemático, mas relativamente objetivo. Em contrapartida, o mesmo já não se pode dizer de afirmações como "esse quadro é bom" ou "eis aqui um ótimo poema". Nesses casos, aumenta a impressão de que o julgamento de valor envolvido é arbitrário, problemático, subjetivista. A razão disto, dirá Hare, é que não compartilhamos amplamente critérios descritivos para esse tipo de julgamento: há muito mais discordância quanto à descrição do que seja um quadro bom do que quanto à descrição de um morango bom! Em suma, os elementos factuais presentes no significado de afirmações valorativas como "esse é um quadro bom" encontram-se em segundo plano, ocasionando uma impressão de preferência subjetiva, contingência, arbitrariedade, opinião, falta de objetividade etc.

Fulford aplica as reflexões de Hare à polêmica entre o modelo médico e a antipsiquiatria. Critica justamente a ideia comum a ambos os polos de que o significado das chamadas doenças somáticas não inclua valores (mas apenas descrições de estruturas e funções) e que isso as torna menos problemáticas do ponto de vista conceitual do que as patologias mentais, claramente inundadas por julgamentos valorativos. Para Fulford, em ambos os casos, fatos e valores se encontram entrelaçados, sem qualquer fosso ontológico. Não há dicotomia aí, mas apenas distinções.

No caso das doenças somáticas, os elementos factuais e descritivos do seu significado ocupam o centro da cena, assim como em "morangos bons". Todos estamos de acordo quanto aos critérios utilizados para se descrever o valor negativo da experiência de se estar "doente do corpo", que pode envolver determinadas sensações (dor, náusea, tonteira...), alterações do movimento (tiques, paralisias, coreias...) e da percepção (cegueira, surdez...). Nas palavras de Fulford e colegas,

o diagnóstico da medicina do corpo se preocupa com áreas da experiência e do comportamento humano, como dor severa, ameaça de morte e paralisias, onde os valores humanos são relativamente bem compartilhados (o que é bom para um é bom para a maioria). (Fulford, Broome, Stanghellini, Thornton, 2005, p. 30) 
A grande maioria de nós concorda, por exemplo, sobre os critérios de descrição do bom funcionamento de um joelho: ele permite a sustentação do nosso corpo, não dói quando andamos, admite a execução de determinados movimentos, obedece ao nosso controle etc. Esse tipo de compartilhamento chega a ser tão amplo que transcende em alguma medida épocas e culturas. Mas nem por isso os elementos valorativos de "joelho bom" ou "joelho com problemas" estão ausentes, já que essas afirmações estão ligadas diretamente ao campo da ação e das prescrições. Apenas se encontram em segundo plano, atrás dos elementos descritivos compartilhados.

Todavia, quando adentramos o campo psicopatológico, nossos critérios para descrever o valor negativo de algo se tornam bem menos compartilhados. Para começar, há muita heterogeneidade em relação à matéria dos diagnósticos psicopatológicos, que podem incluir variações da vontade, das crenças, da forma do pensamento, do desejo, da identidade pessoal, das emoções, do comportamento, da imagem corporal... até de conceitos complexos como "personalidade"! Quantos de nós compartilham critérios indisputáveis para descrever o bom funcionamento das emoções? Temos uma descrição comum clara para quando um desejo se torna indesejado? Como se descrever a linha de corte entre uma rede de crenças normal e uma patológica? Evidentemente, esse tipo de descrição será pouco compartilhado, abrindo facilmente espaço para a discordância e a controvérsia. ${ }^{5}$ Assim como no julgamento de um "quadro bom" a psicopatologia lida com um baixo compartilhamento de critérios descritivos para os seus julgamentos valorativos, gerando a impressão de falta de objetividade, arbitrariedade, enviesamento político etc.

\section{Por um normativismo deflacionado}

O debate sobre a validade diagnóstica das categorias psicopatológicas atingiu o auge da sua tensão com as críticas colocadas pelo movimento

${ }^{5}$ Em relação a esse ponto, como apontam Fulford, Thornton e Graham (2006, seção 2, capítulo 2), ainda há variações internas ao campo psicopatológico: para certas condições (como as demências, por exemplo), temos mais critérios de descrição de valores compartilhados do que para outras (como o transtorno opositivo-desafiador, por exemplo). 
antipsiquiátrico a partir dos anos 1960 e, sobretudo, com a polêmica em torno da desmedicalização da homossexualidade nos anos 1970 (Bayer, 1981). Que tipo de ciência é essa que determina a validade de uma categoria diagnóstica com base em pleitos de ordem política?, se perguntavam todos. $\mathrm{Na}$ atualidade, essa tensão se reatualiza de muitas formas: na expansão de abordagens naturalistas reducionistas da psiquiatria e em projetos como o RDoC (já citado), desejosos de assentar a psicopatologia em bases descritivas incontroversas; na denúncia da medicalização da existência promovida pela psiquiatria contemporânea feita por pesquisadores de várias orientações (Conrad, 2007; Frances, 2016; Healy, 2002); nos debates sobre a neurodiversidade (Ortega, 2009) e a patologização da transexualidade (Butler, 2009), que nos convocam a novas reflexões sobre o normal e o patológico etc. Nossa hipótese é que no centro dessa tensão há uma discussão tácita sobre o papel desempenhado pelos valores na definição, isolamento e classificação das patologias mentais.

Como se procurou argumentar ao longo deste texto, há uma tendência a discutir o papel dos valores no campo psicopatológico pela adoção de uma dicotomia fato/valor. Em vez de apaziguar tensões e dissolver falsos problemas, esse tipo de posição dicotômica acaba sendo uma fonte suplementar de confusão conceitual. Por isto, pensar em novas descrições para o modo como fatos e valores se fazem presentes nas categorias psicopatológicas constitui um belo exercício de clarificação conceitual, com consequências importantes tanto para a pesquisa empírica quanto para a prática clínica.

Por um lado, não nos parece plausível simplesmente eliminar a dimensão valorativa, em um esforço para extrair das nossas categorias descrições factuais purificadas, como defendem posições naturalistas. Não há condições internas necessárias e suficientes para sustentar um essencialismo dessa espécie no campo psicopatológico, pois síndromes, doenças, traços de personalidade, não são tipos naturais, nem uma representação linguística da estrutura de um mundo preexistente "lá fora". Trata-se de categorias produzidas, antes de qualquer coisa, a partir dos nossos interesses e possibilidades de ação; são recortes do mundo que expressam um pathos inseparável de nossas formas de vida particulares. Como bem formulou Canguilhem (1995, p. 169) "é o pathos que condiciona o logos" e não o contrário.

Todavia, considerar os valores uma dimensão irredutível na organização do campo psicopatológico não deveria colocar em descrédito a pesquisa científica. Pelo contrário! Mais científica e rigorosa se tornará a pesquisa em psicopatologia se for capaz de incluir no seu escopo uma reflexão sobre os valores presentes nas categorias com as quais se trabalha. Dito de outra forma, 
há um "acréscimo de realismo" nesta posição normativista, e não o contrário. Contudo, está-se falando de um normativismo distinto daquele adotado pelo construcionismo social, uma vez que não observa oposição entre valor e validade diagnóstica, nem adota uma "atitude desmascaradora" face ao baixo compartilhamento de critérios descritivos para os valores frequentemente presentes nas categorias diagnósticas. Em outras palavras, trata-se da adoção de um normativismo deflacionado, compatível inclusive com certas formas de naturalismo não reducionista ou pragmático.

Esse normativismo deflacionado, por colocar uma reflexão sobre a dimensão valorativa da psicopatologia no centro do debate, apresenta uma série de vantagens teóricas e práticas: pode propiciar o estabelecimento de acordos mais amplos quanto aos critérios diagnósticos que adotamos, sobretudo no caso de categorias controversas; permite a revisão de categorias diagnósticas derivadas de julgamentos que passaram a ser considerados politicamente reacionários, nocivos ou iatrogênicos; ${ }^{6}$ abre vias de clarificação do conceito mesmo de transtorno mental, suas subcategorias e as práticas de cuidado que ele convoca; traz para a pesquisa e para a clínica os valores sustentados por pacientes, seus familiares e comunidades locais, tanto em suas singularidades como em suas particularidades culturais compartilhadas. Como se procurou argumentar, nada disso faz da psicopatologia um campo cientificamente imaturo ou ameaça o rigor da pesquisa teórico/clínica. Pelo contrário, apenas expõe como esse campo é valorativamente complexo e, por isso mesmo, propício a reflexões sofisticadas sobre o significado mesmo de cada uma de suas categorias diagnósticas.

\section{Referências}

American Psychiatric Association (2014). Manual Diagnóstico e Estatístico de Transtornos Mentais, DSM-5. Porto Alegre, RS: Artmed.

Barrett R. (1998). La traite des fous: La construction aociale de la schizophrénie. Paris, IDF: Les Empêcheurs de penser en rond.

Bayer, R. (1981). Homosexuality and American psychiatry: the politics of diagnosis. New York, NY: Basic Books.

Benedict, R (1934). Anthropology and the Abnormal. Journal of General Psychology, 10, 59-80.

Boorse, C. (1975). On the distinction between disease and illness. Philosophy and Public Affairs, 5, 49-68. 


\section{ARTIGOS}

Boorse, C. (1977). Health as a theoretical concept. Philosophy of Science, 44(4), 542-573.

Boorse, C. (2002). A rebuttal on functions. In A. Ariew, R. Cummins, M. Perlman (Eds.). New essays in the Philosophy of Psychology and Biology (pp. 63). Oxford: Oxford University Press.

Boyle, M. (1990). Schizophrenia: A Scientific Delusion? London, UK: Routledge.

Butler, J. (2009). Desdiagnosticando gênero. Physis: Revista de Saúde Coletiva, 19(1), 95-126.

Canguilhem, G. (1995). O normal e o patológico. Rio de Janeiro, RJ: Forense Universitária.

Conrad, P. (2007). The Medicalisation of Society: On the Transformation of Human Conditions into Treatable Disorders. Baltmore, MD: John Hopkins University Press.

Conrad, P., \& Potter, D. (2000). From Hyperactive Children to ADHD Adults Observations on the Expansion of Medical Categories. Social Problems, 47(4), 559-582.

Cooper, R. (2007). Psychiatry and Philosophy of Science. Stocksfield, NE: Acumen.

Damazeux, S. (2013). Qu'est-ce que le DSM? Genèse et transformations de la bible américaine de la psychiatrie. Paris, IDF: Itaque.

Foucault, M. (1972). Histoire de la folie à l'âge classique. Paris, IDF: Gallimard.

Frances, A. (2016). Voltando ao normal: como o excesso de diagnósticos e a medicalização da vida estão acabando com a nossa sanidade e o que pode ser feito para retomarmos o controle. Rio de Janeiro, RJ: Versal Editores.

Fulford, K.W.M. (1989). Moral Theory and Medical Practice. Cambridge, MA: Cambridge University Press.

Fulford, K. W. M. (2001). What is (Mental) Disease - open letter to Christopher Boorse. Journal of Medical Ethics, 27, 80-85.

Fulford, K. W. M. (2004). Facts/Values: Ten Principles of Values-Based Medicine. In J. Radden (Ed.). The Philosophy of Psychiatry: A Companion (pp. 205-234). New York, USA: Oxford University Press.

Fulford, K. W. M., Broome, M. Stanghellini, G., \& Thornton, T. (2005). Looking with both eyes open: fact and value in psychiatric diagnosis? World Psychiatry, 4(2), 78-86.

Fulford, K. W. M., Thornton T., \& Graham G. Oxford Textbook of Philosophy and Psychiatry. New York, NY: Oxford University Press, 2006.

Giroux, É. (2010). Après Canguilhem: définir la santé et la maladie. Paris, IDF: Presses Universitaires de France. 
Hacking, I. (1999). The Social Construction of What? Cambridge, MA: Harvard University Press.

Healy, D. (2002). The Creation of Psychopharmacology. Cambridge, MA: Harvard University Press.

Horwitz, A. (2013). The Sociological Study of Mental Illness: A Critique and Synthesis of Four Perspectives. In C. Aneshensel, J. Phelan, \& A. Bierman (Eds.), Handbook of the sociology of mental health, second edition (pp. 95-114). New York, NY: Springer.

Kirk, S., \& Kutchins, H. (2008). The Selling of DSM: The Rhetoric of Science in Psychiatry. New Brunswick, NJ: Aldine Transaction Publishers.

Lovell, A., \& Moutaud, B. (2017). Sociologie des troubles psychiatriques, In J.-D. Guelfi, \& F. Rouillon. Manuel de Psychiatrie (3ème éd., pp. 93-104). Paris, França: Elsevier-Masson.

Nadesan, M-H. (2005). Constructing Autism: Unravelling the 'thuth' and understanding the social. New York, NY: Routledge.

Ortega Francisco (2009). Deficiência, autismo e neurodiversidade. Ciência \& saúde coletiva, 14(1), 67-77.

Putnam, H. (2002). The Collapse of the Fact/value Dichotomy and Other Essays. Cambridge, MA: Harvard University Press.

Scheff, T. (1984). Being Mentally Ill. A sociological theory (2 ${ }^{\mathrm{a}}$ ed.). New York, NY: Aldine.

Szasz, T. (1961). The myth of mental illness: foundations of a theory of personal conduct, New York, NY: Hoeber-Harper.

Young, A. (1995). The Harmony of Illusions: Inventing Post-Traumatic Stress Disorder. Princeton, NJ: Princeton University Press.

Zachar, P. (2000). Psychiatric Disorders are not Natural Kinds. Philosophy, Psychiatry, \& Psychology, 7(3), 167-182.

\section{Resumos}

(Psychopathology beyond the fact/value dichotomy)

The ontological status of mental disorders raises a classical debate between naturalist and social constructionist perspectives. With conceptual tools borrowed from the philosophy of psychiatry, we claim that, although seemingly opposite, both naturalist and social constructionist arguments incur in a fact/value dichotomy. As an alternative to this classical polarization, we suggest a deflated normativity position capable of integrating factual descriptions and values to psychopathology.

Key words: Philosophy of psychiatry, normativity, naturalism, social constructionism 


\section{ARTIGOS}

(La psychopathologie au-delà de la dichotomie fait/valeur )

Le statut ontologique des troubles mentaux soulève un débat classique entre des perspectives naturalistes et constructivistes sociales. Avec des instruments conceptuels de la philosophie de la psychiatrie, on soutient que, bien qu'apparemment contraires, les positions naturalistes et constructivistes sociales retombent dans une dichotomie fait/valeur. Comme alternative à cette polarisation classique, nous suggérons une position normativité faible, capable d'intégrer des descriptions et des valeurs factuelles à la psychopathologie.

Mots clés: Philosophie de la psychiatrie, normativisme, naturalisme, constructivisme social

(La psicopatología más allá de la dicotomía hecho/valor)

El estatuto ontológico de los trastornos mentales suscita un debate clásico entre las perspectivas naturalistas y construccionistas sociales. Con instrumentos conceptuales de la filosofia de la psiquiatría, se argumenta que, a pesar de ser aparentemente contrarias, las posturas naturalistas y construccionistas sociales incurren en una dicotomía hecho/valor. Como alternativa a esa polarización clásica, se sugiere una postura normativista deflacionada capaz de integrar, a la psicopatología, descripciones factuales y valores.

Palabras clave: Filosofía de la psiquiatría, normativismo, naturalismo, construccionismo social

(Psychopathologie jenseits der Dichotomie Tatsache/Wert)

Der ontologische Status von Geistesstörungen ist seit jeher Gegenstand einer klassischen Debatte zwischen naturalistischen und sozialkonstruktivistischen Standpunkten. Anhand des Begriffsapparats der Philosophie der Psychiatrie wird argumentiert, dass naturalistische und sozialkonstruktivistische Standpunkte, welche scheinbar gegensätzlich sind, eigentlich eine Tatsache/Wert Dichotomie bilden. Als Alternative zu dieser klassischen Polarisierung, schlagen wir eine abgeschwächte normative Stellung vor, die es erlaubt, Tatsachenbeschreibungen und Werte in die Psychopathologie zu integrieren.

Schlüsselwörter: Philosophie der Psychiatrie, Normativismus, Naturalismus, Sozialkonstruktivismus 
Citação/Citation: Venturi, C. B. (2018, setembro). A psicopatologia para além da dicotomia fato/valor. Revista Latinoamericana de Psicopatologia Fundamental, 21(3), 589-610. http:// dx.doi.org/10.1590/1415-4714.2017v21n3p589.10.

Editores do artigo/Editors: Profa. Dra. Ana Maria Rudge e Profa. Dra. Sonia Leite.

Recebido/Received: 15.4.2018/ 4.15.2018 Aceito/Accepted: 22.6.2018 / 6.22.2018

Copyright: (C) 2009 Associação Universitária de Pesquisa em Psicopatologia Fundamental/ University Association for Research in Fundamental Psychopathology. Este é um artigo de livre acesso, que permite uso irrestrito, distribuição e reprodução em qualquer meio, desde que o autor e a fonte sejam citados / This is an open-access article, which permits unrestricted use, distribution, and reproduction in any medium, provided the original authors and sources are credited.

Financiamento/Funding: $\mathrm{O}$ autor declara não ter sido financiado ou apoiado / The author has no support or funding to report.

Conflito de interesses/Conflict of interest: $\mathrm{O}$ autor declara que não há conflito de interesses / The author has no conflict of interest to declare.

\section{Camilo Barbosa Venturi}

Professor Adjunto do Instituto de Psicologia da Universidade Federal do Rio de Janeiro IP-UFRJ (Rio de Janeiro, RJ, Br); Doutor em Saúde Coletiva pelo Instituto de Medicina Social da Universidade do Estado do Rio de Janeiro - IMS-UERJ (Rio de Janeiro, RJ, Br). camiloventuri@id.uff.br

This is an open-access article, which permits unrestricted use, distribution, and reproduction in any medium for non-commercial purposes provided the original authors and sources are credited. 